\title{
A REVIEW AND CONCEPTUALIZATION FOR SOCIAL COLLABORATION ACHIEVEMENT IN BIM CONSTRUCTION CONTEXT
}

\author{
Raja Nor Husna Raja Mohd Noor *1, Che Khairil Izam Che Ibrahim² and Sheila Belayutham ${ }^{3}$ \\ ${ }^{1}$ Faculty of Civil Engineering, Universiti Teknologi MARA, 13500 Permatang Pauh, Pulau Pinang, Malaysia. \\ ${ }^{2,3}$ Faculty of Civil Engineering, Universiti Teknologi MARA, 40450 Shah Alam, Selangor, Malaysia
}

E-mail: * rajanorhusna@ppinang.uitm.edu.my

\begin{abstract}
The emergence of widespread advanced digital technologies being utilised into the construction industry practices adds a new dimension to the better integration and collaboration of construction projects. Nowadays, Building Information Modelling (BIM) is recognized as a modern tool to enhance greater visualisation of project information and provides opportunities for an effective communication platform within a multi-organisations context. Despite the wave of enthusiasm for BIM studies having shown exceptional benefits, the context of social collaboration across multi-organisations is still limited. Thus, this paper aims to present the review of key indicators towards social collaboration achievement within multi-organisations in the BIM construction context. Based on a comprehensive review, five key indicators are identified that contribute to the social collaboration achievement in BIM construction context. Including organisational perspectives, foundational setting, behavioural perspective, educational perspective and enforcement platform. The findings also revealed the extend of the spectrum of collaboration literature in the context of construction domain particularly on characterisation and its importance towards social collaboration within a multi-organisation in digital environment.
\end{abstract}

Keywords: Building Information Modelling, Construction Projects

\section{INTRODUCTION}

In the era of digitalisation, the incorporation of new technologies are capable to drive the innovation in the construction sector and is considered vital to increase greater productivity throughout the project life cycle. The widespread of this advanced technological adoption also encourages the change of roles within multi-organisations and hence maximizing collaboration within multi-organisation collaboration.

In particular, Building Information Modelling (BIM) has been known to be one of the most advanced digital technologies' tools capable of stabilizing the management of information and improve the collaboration within multi organisations in overall construction project cycles (Ya'acob et al, 2018). Additionally, these benefits vary either for short or long term investment, including the ability to deliver precise project information and providing greater visualisation of project information via multi-dimensions modelling capabilities (Hosseini et al, 2016), enhancing the quality of project communication across multi-actors (Zahrizan et al, 2014; Musa et al, 2018), providing the platform of shared knowledge and decision making as well as management of data and resources within different organisations at different phases in the construction projects (Memon et al.,2014). 
In spite of its well documented benefits related to the collaboration, the full potential of BIM is still not fully exploited (Merschbrock \& Munkvold, 2015) consequently affecting the continuous and consistency of BIM collaboration practice within project organisation (Enshassi et al, 2016; Zheng et al., 2017) contributing to the slow pace of implementation of BIM. Additionally, Yusuf et al. (2015) and Ishak et al. (2017) highlighted the main challenges for the multi-organisation to achieve success of collaboration practices in BIM project is inability to embrace the social aspect which could affect the diffusion of BIM practice. As emphasised by Cidik and Boyd (2019), social aspect is known as one of the drivers of mutual relationship that can influence the success of collaboration between interdisciplinary organisations in managing projects.

The main possible reasons in terms of social aspect contributing to this serious case are due to the behaviour aspects within multi-organisations including the reluctance of project members in the organisation to change their attitude from traditional working practices to the adoption of modern technology (Olawumia et al, 2018; Mohammad et al, 2019), having 'silos' mentalities and operated in isolated working practices (Merschbrock \& Munkvold, 2015; Akponeware \& Adamu, 2017; Liu et al, 2017), self-interest practices (Zheng et al, 2017), weaknesses of specific disciplines (i.e. Civil and Structure) to integrate the innovative technologies to keep up with their counterparts from the other engineering disciplines (i.e. Electrical, Mechanical and Automation) (Oesterreich \& Teuteberg, 2016), do not have precise knowledge and clear understanding of the potential value of the BIM philosophy (Liu et al., 2017) and the organizational arrangement is still working in the traditional routine without having a clear vision of BIM practice (Whyte \& Lobo, 2010) which will impair of the effective collaboration among construction organisation.

Thus, Liu et al. (2017) and Oraee et al (2017) stated that these issues are classified as the blocking factor contributing to the need of efforts to focus more on social collaboration aspect among multi-organisations in the context of BIM construction projects. Despite collaboration being an important success factor of BIM, BIM collaboration research, particularly in the context of social collaboration has not reached a level that it should have achieved (Oraee et al., 2017). Therefore, to address the gap of knowledge in this research context, the comprehensive review for key indicators of social collaboration achievement in BIM construction context has been carried out towards driving the higher productivity in enhancing the success of BIM implementation.

\subsection{The debate on the evolution of BIM as a collaboration platform}

To date, over the past few decades, the potential of study related to the collaborative practice context, focusing on the BIM spectrum, has gained serious attention. To provide an insight towards the trends and styles of BIM research, the related literature can be divided for four main sub-periods which contain relevant research context focussing on the setting and publication years.

Recently, various scholars has shown greater interest specifically on the benefits of values for BIM and the practice of collaborative working. Most of the research trends for the beginning of literature trends for BIM collaboration has emphasized on the determination on the drivers and antecedents influencing the utilisation of BIM as collaboration technologies. Additionally, in this period, most of the research studies are mainly focussed more on European settings (e.g. Greece).

By referring to the previous review among scholars, specifically in duration between 2011 to 2013, mainly concentrated on Canada, UK and Australia settings show the increasing revolution of research focussing on the general concept for BIM collaboration to the determination for information sharing and exchanges in the digital spectrum, concentrate on the evidence of literature related to the BIM as collaborative practice and developing framework including the technical aspect for BIM partnering and requirements towards BIM implementation.

Moreover, between the period of 2014 to 2016, in the Nordic countries (e.g. Finland and Norway), UK and Asia settings (e.g. Korea and Taiwan), most of the research context has extended its spectrum more on analytical research studies, assess the several system and concepts for BIM collaboration. Research carried out by several scholars has begun to emphasize on the diverse types of research methods from case studies approaches to modelling. Furthermore, several scholars initiate the identifying practice for BIM collaborative in actual cases (e.g. hospital projects).

In addition, most of studies broadened the understanding of the practice of BIM collaborative focusing on the effect of BIM as collaborative technologies concentrating on the organisations aspects have begun to develop in the fourth sub period $(>2017)$. In the last 10 years, the critical review on the available literature started to take place 
on the relevant research studies in Asia (e.g. Hong Kong and China) and US settings.

\subsection{The relevancy of BIM as collaboration approach in construction literature}

Collaborative being seen as a practice that could influence the success of projects through the shared physical spaces and collaborative practice (Kokkonen \& Anne, 2018), sharing information and processes via interacting, communicating, exchanging, coordinating and approving, to share visions among stakeholders and to maximize the multi-organisation effort on a particular job (Illich et. al., 2006; Kokkonen \& Anne, 2018).

However, Oraee et al. (2019) stated that there is the radical change in recent years where the introducing of web-based applications concentrates on information technology (IT) in BIM construction view and the environment of collaboration practice. In essence, several scholars including Bassanino et al. (2014) and Alreshidi et al. (2016) highlighted that through technical capabilities of BIM in driving a collaborative nature have contributed to the major motivators to enhance collaboration within multi-organisation where most of them are in the different locations but capable to use shared databases through BIM as information technology.

Previous literature (e.g. Oraee et al., 2017) indicated that the success of collaborative working practice can be determined based on the ways on how the implementation of BIM has been carried out. Nevertheless, the exploration on previous research need to be concentrated on the achievement of social collaboration in BIM spectrum has been one of the significant aspects that need to be concern rather than only to review the broader spectrum of literature related to the BIM collaboration especially in construction aspect.

The theoretical framework concentrated on the technical requirement has been created using BIM servers where functioning as inter disciplinary collaboration medium (Singh et al, 2011). Moreover, in order to expedite the collaborative environment through digital platform, therefore more focus should be placed on supporting the communication media, process management, information sharing and also to have privacy and flexible system configuration.

Towards enhancing the experience among multi-organisation in the BIM utilisation, there is a need to focus on having integrated platform including the BIM cloud (Redmond et al., 2012). This BIM cloud is suggested to be used due to the capability to function as an exchange mechanism driven to the effectiveness of collaboration through exchanging and sharing data information. This is similar with the study done by Petri et al. (2017) in United Kingdom, where the Comet Cloud System has been used to create federated cloud that facilitate coordination among multi-site construction projects through supporting the data sharing and the process of interoperability based on various stakeholders involved in the AEC project life cycle. This is also supported by Zhang et al. (2017) where has purpose multi-server approach based on a private cloud platform for information interoperability and cross-party collaboration and capable to maintain the privacy and ownership of the data. In addition, Merschbrock and Munkvold (2015) highlighted that inter organizational factors in major domains influenced the expansion of BIM technology specifically on managerial, environmental, and technological challenges within project level and individual aspect where has be proven based on the case study that has been carried out for large healthcare project in Norway where this project also been awarded for BuildingSMART in 2015 award.

In different perspective, Zheng et al. (2017) stated that by creating on the outcome linked benefit sharing model (OLBSM) it could be as one of the incentivize supporting elements among inter organisation focussing on the BIM collaboration where concentrate on the objectives of BIM, inclusive process, procedures also the rigorous analysis in diverse incentive alignment options in order to evaluate possible impacts efforts and beneficiaries provided. While, the study in Canada identified that there are five cognitive factors that influenced the collaboration among individuals using BIM where includes the intentions, incentives, requirements and capabilities especially in the context of architecture, engineering and construction industry (Poirier et al., 2017).

Moreover, in another study carried through focus group discussion and interview approach found there are eight concepts concentrated into three domains including technology, process and people that are capable to influence the development of BIM in term of collaboration perspective (Liu et al., 2017). While, the research carried out by Kapogiannis, and Sherratt (2018) highlighted the effects of the utilisation for integrated collaborative technologies which can influenced the team collaboration among organisations where this collaborative environment could assist the organisation in order to access diverse the information in the different places. Besides, the organisations also enable to exchange knowledge and gained awareness related to the project that has been carried out where directly influenced them specifically understanding the project brief through digital environment medium. 
In another study, Al Hattab \& Hamzeh (2018) has found that the fundamental conditions including the collaboration and the changes of traditional mind sets can improve the design workflow and achieve the full potential of BIM as collaborative tool by considering social interaction mechanism and information flow dynamics. On the other hand, managers also can monitor construction progress and approximate the cost information in the actual time duration by specifically utilize BIM with virtual reality (VR) through the ability of this technology in terms of traceability and visibility functions (Li et al., 2018). Moreover, towards to achieve efficiency and effectiveness of decision making, collaboration, supervision and daily operation, there is a need to utilize an Internet of Things (IoT) where capable to provide various benefits as decision support services within diverse of organisations. Van Gassel et al. (2014) through the desk study and case study found that there are several variables needed in order to have an active relationship in the automated collaborative where includes the 'aim of meeting', 'control of meeting', 'participants', 'tools' and 'outcomes' that suitable to describe successful collaborative working in design meetings.

In addition, Burcin et al. (2011); Bozoglu (2016) and Puolitaival \& Kestle (2018) has emphasized on a modular approach to promote BIM enabled learning as BIM education in curriculum and a course development in universities levels where can enhance experience, collaboration and coordination between both futures graduates engineers and architects and enhance the collaboration in BIM construction projects as a strategy in order to meet the demands from industry by gaining the knowledge sharing, decisions making, enhance BIM skills and drives the integrated communication among them.

Overall, based on comprehensive reviews, it can be concluded that most scholars are not concentrated to consolidate what it takes to ensure the greater achievement for social collaboration in the context of BIM construction, however most of scholars in the literature are more focused on understanding the collaboration using BIM and emphasize to investigate the factors for BIM collaboration in terms of diverse contexts. Oraee et al. (2017) stated that the research carried out related to social aspects in terms of BIM collaboration is still limited compared to the other studies and this is supported by Kokkonen \& Vaagaasar (2018) who highlighted that this study has been proven to be more challenging. Consequently, the objective of this study focuses on identifying the key indicators of social collaboration achievement as an approach to promote deeper understanding of the concept related and also of social collaboration in utilization of BIM, this paper focuses specifically on identifying the key indicators of social collaboration and attempts to categorize them, to attain a clear view into how they can influence the better achievement of collaboration in BIM construction project.

\section{METHODOLOGY OF RESEARCH}

In this comprehensive review, the analysis via systematic literature review has been conducted through various literature in order to assess the consistency and adequacy of scientific attempts as well as uncover gaps within the existing literature on a topic (Mulrow, 1994 \& Oraee et al., 2017). Also the systematic review is intended to develop existing body of knowledge for research (Transfield et al., 2003) through review of the available 'best evidence' in order to provide insights and guidance in completing the research need. The guidelines made by several scholars (e.g. Nakamba et al., 2017; Lu et al., 2017) has been referred in order to select the initial article that is related to the research study. In this systematic literature review consists of three main steps as following procedure:

\subsection{Select data sources and perform preliminary search}

To acquire as many papers as possible that relevant to BIM collaboration in construction context, the articles introduced specifically in the construction engineering management journals and conferences based on their inclusion in the top-tier leading construction journals (Chau., 1997; Hong et al., 2012; Lu et al., 2015; Nakamba et al., 2017) has been identified. Therefore, 21 journals and conferences were selected and considered through preliminary search where namely: Automation in Construction (AUTCON), Engineering, Construction, and Architectural Management (ECAM), Construction Management and Economics (CME), International Journal of Project Management (IJPM), Construction Economics and Building (CEB), Journal of Construction Engineering and Management (JCEM), Advanced Engineering Informatics (AEI), Journal of Information Technology in Construction (ITCON), Architectural, Engineering and Design Management (AEDM), Built Environment Project and Asset Management (BEPAM), Project Management Journal (PMJ), Journal of Computing in Civil Engineering (JCCE), Journal of Management in Engineering (JME), Proceedings of Institutional of Civil Engineers Management 
Procurement and Law's Source Details (PICEMPL), Computer-Aided Civil and Infrastructure Engineering (CACIE), International Journal of Civil Engineering and Technology (IJET), Canadian Journal of Civil Engineering (CJCE), Building Research and Information (BRI), Malaysian Construction Research Journal (MCRJ), Construction Economics and Building (CEB), Construction Innovation, Information, Process and Management (CI) and Association of Researchers in Construction Management (ARCOM). In addition, SCOPUS database was chosen as the main searching sources because it considered to have broad and multidisplinary scope and are the most commonly used sources for review studies (Nakamba et al., 2017).

\subsection{Filter article based on construction management journals, conferences articles and years of published by referring to the subjects, titles, keywords and abstract in the BIM context}

In addition, in order to search on the availability of literatures, most of articles published starting from 2008 to 2018 were included in this research study by supporting by Oraee et al (2017) where this research study concentrates on the collaboration context specifically in BIM. In addition, the following phrases in titles, subjects, abstracts or keywords: BIM, collaboration, social, collaborative and construction has been used in order to narrow the scope of research area within 21 selected journals and conferences. Moreover, based on the results carried out, it shows the broad selection of works that involved qualitative, empirical, book reviews, descriptive articles and technical notes.

\subsection{Identify extract research articles}

Nevertheless, to gain a clear and comprehensive scope of the study, another approach concentrated on the search view was performed by referring to the two keywords through the initial selected BIM articles including collaborative and collaboration. Moreover, to determine the applicable list of selected literature, the abstracts of articles are critically reviewed. Thus, 27 selected articles within the context of BIM social collaboration were determined and reviewed, out of the 173 retrieved journal and conferences articles through the diverse of initial selection.

\section{CONCEPTUALIZATION FRAMEWORK FOR SOCIAL COLLABORATION IN BIM CONSTRUCTION CONTEXT}

This research study outline upon 27 selected articles by considering ten related models including CoSpaces Collaborative Working Model (CCWM) proposed by Patel et al. (2016), Key Factors of BIM Implementation Framework or Guideline by Kouch et al (2019), Collaboration Pentagon developed by Oraee et al. (2017), BIM Framework by Succar (2009), Conceptual BIM Collaboration model developed by Lu et al. (2013), Relationship-based Procurement (RBP) Collaboration Framework established by Walker and Lloyd-Walker (2015), BIM Competency Assessment Framework (BIMCAT Framework) by Giel and Issa (2016), Leavitt's Sociotechnical Collaboration Model by Merschbrock et al (2018), A Conceptual Framework For A BIM-Based Collaboration Platform Supported by Mobile Computing by Chen (2011) and Codes, Concepts and Categories of BIMCollaboration Effects Model by Liu et al (2017), thus, the nexus of social collaboration achievement have been critically synthesised and five key indicators has been determined where clearly divided into two level or layer including the Push-Factor for External Level (Outer Layer) and Push-Factor For Internal Level (Inner Layer) as illustrated in Figure 1. Push factor for external level consist of core sources and push factor for internal level act as complementary of core sources that would influence the successful of social BIM collaboration. In particular, these elements are related to social collaboration in BIM-based projects including Foundational setting, Behavioural perspective, Organisational perspective, Educational perspective and Enforcement Platform. However, these five main indicators are interconnected and can effect each other where believed to be capable of driving and aligned BIM collaboration. Thus, the details explanation for each element has been discussed in the following sections.

\subsection{Foundational setting}

In overall, in order to reinforce and support the social collaboration aspect in the BIM context, there is a need to be concerned on the Foundational setting as one of the vital indicators that need to be emphasized. According to Akponeware and Adamu (2017) and Liu et al (2017), BIM has been clarified as greater setting medium 
in order to strengthen the management and integration of coordination among interdisciplinary organisations. Moreover, the utilisation of digital tool, web services and network in the BIM context significantly provided diverse benefits including the delivering of precise construction information, providing better visualisation, afford effective communication and also interaction platform through the capabilities of multi-dimensions modelling, facilitate synchronisation and consistency of common data used, support visual communication, (create, manage, share and exchange information and knowledge, documentation through interdisciplinary and intra disciplinary team), easily updated any progress and monitoring work progress, provide a platform for project teams to effectively interact in the real-time visualization and monitoring of activities and tasks, provides a secure and scalable storage and retrieval of building data, automatically federates and governs distributed BIM data in a consistent and managed way and functioning as BIM governance platform (e.g. message-based platform; cloud based information sharing; social networking; common data environment (CDE), internet of things (IoT); augmented reality (AR); federated cloud; social-media; webinar; integration of social network services (SNS) with AR; AR through mobiles servicessmartphone, tablet, web based; Comet cloud engine; cloud based BIM governance platform; Semantic web, Aconex cloud; and Own Cloud) (Merschbrock et al., 2018; Wong, 2018). Several scholars including Singh et al. (2011) argued that there is a need to enhance and support more on the technical requirements in order to facilitate the effectiveness of technology utilisation and also management aspect within social interaction within inter disciplinary organisations.

In addition, integrated modelling, software and system in BIM give an opportunity to the industry players to build a setting platform allowing multi-organisations to work collaboratively (Chen, 2014). Through the observation of existing literature, the other benefits that can be realised via the integration of modelling (e.g. quality function deployment (QFD) model; online collaborative modelling; model collaboration system (MCS); four-dimensional (4D) BIM (3D BIM plustime); BIM server; governance model via comet cloud) in BIM is the support of team member from multiple discipline in the collaborative BIM model, enhance the visualization and communication of construction plans and milestone among project members, functioning as multidisciplinary collaboration form with open source BIM server, ensuring all team members are working from the same data and also enable multi-actor, multi discipline and lifecycle management of BIM documents and model-based data (Eleftheriadis et al., 2018; Ma et al, 2018). Another scholars have discussed on the added value of having such software systems (e.g. BIM based collaborative system; Con BIM-IM system; Con BIM-SM system; web system; and Kan-BIM software system) in $\mathrm{BIM}$ integration including to improve construction management performance; provide the interface sharing system and effective communication; enhance visualization of work flow in control system where enable pull flow and deeper collaboration teams on and off site; facilitating information distribution and sharing among project teams; and sharing as-built schedule information in construction project (Sack et al., 2010; Ma et al., Tserng et al., 2014).

Another element that related to the social digital collaboration is interoperability. Interoperability is essential approach to support interaction between project teams where they need to have standardization of various model or tool where model created need to be compatible with other software tools so that they can be easily translate into a file format and information be transferred effectively (Jin et al., 2018; Wong, 2018). Thus, the technological platform is plausible supporting elements to encourage a seamless of social BIM collaboration.

\subsection{Behavioural perspective}

According to Ibrahim (2013), the most major factor capable to support the social collaborative working practice is known as Behaviour which is driving the success of digital environment. In addition, Kapogiannis and Sherratt (2018), highlighted that in order to achieve the collaborative environment, there is a need to focus more on proactive behaviour context. Moreover, a solid combination between behavioural best practices and human-centric approach among inter organisation will assist everyone to enhance their skills and develop knowledge towards the common goal. Merschbrock and Munkvold (2015) and Lu et al. (2013), highlighted the importance of roles and responsibilities which enables to strengthen the collaboration in terms of human relationships.

In the context of digital environment, Porwal and Hewage (2013), stated that the individual behaviour may also effect the collaboration based on the transformation of traditional roles to the modern roles context. Besides, in order to achieve the collaborative activities, the multi organisation should focus on various skills needed (Patel et al., 2012). Therefore, the initiative in embedding specifically for behavioural skills via digital literacy, experience and knowledge has been trusted being applied to drive the social practices towards the better achievement of collaboration in BIM context. Oraee et al. (2017), highlighted the importance of integration of expertise and skills of individuals among multi organisation context capable to enhance and provide a better social networking. 


\subsection{Organisational perspective}

Zheng et al. (2017) and Lu et al. (2013) stated that multi organizations has used the collaboration platform in the context of digital environment. The importance effects of utilization of BIM in the context of social collaboration would come based on integration of organizations involved in the process of delivering aspect using BIM on the related activities and also task and activities via effective collaborative working initiatives. Patel et al. (2012) highlighted the increase of the effectiveness of collaboration through the consistency of interaction processes including communication, information sharing and collective decision making.

In addition, Lu et al. (2013) stated that the institutional support received by the individuals could encourage their consistency and commitment to the project. Besides, in enhancing the commitment of multi organisation in utilize the BIM as collaborative technologies and also enhance their productivity through strong relationship, there is a need optimisation of organisational support in psychological perspectives. Moreover, to support the digital environment, there is importance of framing the BIM in the projects within collaborative environment practice (Poirier et al., 2016; Oraee et al., 2017) which influence the positive culture of social levels among individuals, teams and organizations.

Additionally, in order to resolved the complex nature including heterogeneous, socialization and peculiar nature of construction projects, there is a need to be concerned specifically on social collaboration in BIM context. Moreover, the evolution of BIM throughout the building life cycle has becoming the significant contribution for better coordination and integration of people, process, place and technology. Based on the critical review of literature, besides the technology features, the behavior of organizations is considered as significant driven factor in enhancing an effective social collaboration in BIM construction context.

Nevertheless, the contractual and technological has been considered as important platform, in order to govern the structure of social collaboration. In addition, the important role to ensure the consistency of social technical aspect within the collaboration can been influenced by the collective behavior, processes involved, organizational support provided and instilling proactive. 


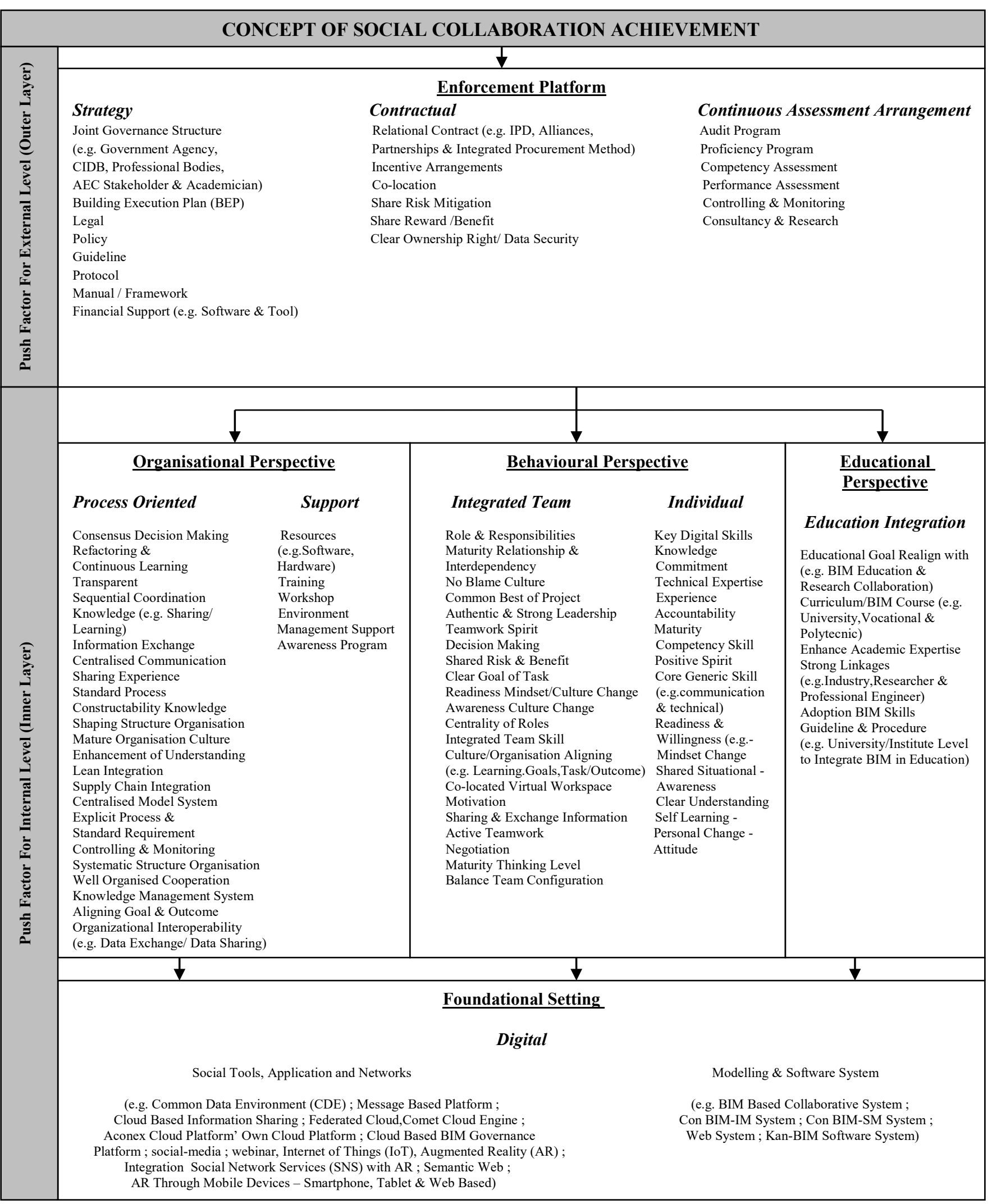

Figure 1: Social Collaboration Achievement Framework for BIM-Based Project 


\subsection{Educational Perspective}

The good and continuous relationship between project members and organisation through BIM collaboration can be strengthen through integration of education platform. Mamter and Aziz (2016) define education is a pivotal and driven element for BIM social collaboration. Thus, the existence of universities and other learning institution developing and delivering educational programs related to BIM is a significant and plausible in enhancing the BIM diffusion (Succar, 2009 \& Burcin et al., 2011). Therefore, there is a need to have educational goals related to BIM by expressed as learning outcomes where these goals can inform curriculum and course design and facilitate the development of BIM guideline and learning modules where can guide educators to integrate BIM in curriculum programme and measure the competency skills of students and academic staff using common reference with standardised competency (Succar, 2009; Succar et al, 2013; Pikas et al., 2013; Zharizan et al., 2014; Harris et al., 2014; Ding et al., 2015; Mamter \& Aziz, 2016; Abdulaal et al., 2017; Deniz, 2018).

In addition, the introducing of BIM in the education for students especially in curriculum, course delivery and research collaboration would give the preliminary exposure, real practical or training, depth understanding and knowledge, adoption BIM generic skill, and experience of a project-based collaboration and equipped with BIM capabilities where will reflect the current and future industry practice for graduate to be employable in the industry (Kihong et al., 2011 ; Burcin et al., 2011; Zahrizan et al., 2014; Oraee et al., 2017). This supported by Harris et al (2014) where agree that this collaboration with universities through research collaboration and curriculum designed for students is one of the important factors that could increase the pace of implementing BIM where would produce students who ready with 3D parametric model and also give the opportunities for university researchers to conduct research related to BIM and they could collaborate with industry to identifying the needs and area for exploration. In addition, the adoption of BIM education in university would influence the academic to be expert (e.g. lecturers and technician) where specialize in BIM and directly assist the BIM deployment (Succar et al., 2013).

Moreover, the involvement of many countries with the BIM adoption and implementation strategies and support mechanism via academia and industry collaboration (Bozoglu, 2016; Puolitaival \& Kestle, 2018) would provide strong linkages between professional engineers (PE), industry, academic staff and students (Owen et al., 2010; Zahrizan et al., 2014).Therefore, the action in considering BIM education among students and academic staff in university and others institute are the right way where would provide a sufficient supply of BIM experts for future in the industry.

\subsection{Enforcement platform}

Enforcement platform is a main necessity platform that need to be concern to strengthen and ensure the achievement of BIM collaboration. Supported with Zahrizan et al (2014) and Harris et al (2018) where enforcement is a main driving platform to enhance BIM collaboration. Even though, the organisation context, behaviour context, educational context and foundational platform have been emphasized in the BIM collaboration, the enforcement platform where leading by joint governance structure (e.g. government agency, CIDB, professional bodies, committees and architecture, engineering and construction (AEC) stakeholders and academic expertise) are considered as external push factor (outer layer) desired in producing the complementary path through mandating, regulating and facilitating any strategies, contractual and continuous assessment arrangement related to the BIM collaboration where prompting the BIM deployment across project members, organisation, industry or whole markets (Succar, 2009; Ibrahim, 2013; Zahrizan et al., 2014; Alreshidi et al., 2016; Giel \& Issa (2016); Kouch et al., 2018; IECEE, 2019). Several studies have discussed on the significant to have strategies (e.g. legal, policy, guideline, protocol, standard, manuals or framework, building execution plan (BEP), financial support and awareness program) in achieving successful of BIM collaboration (Succar, 2009 ; Wong et al., 2010 ; Olatunji, 2011; Zahrizan et al., 2014 ; Harris et al., 2014 ; Mignone et al., 2016; Giel \& Issa, 2016; Mamter \& Aziz, 2016; Abdulaal et al., 2017 ; Liao et al., 2017 ; Merschbrock et al., 2018; Kouch et al., 2018).

Apart from having collaborative in enforcement of BIM strategies, other influencing mechanisms such contractual framework is vital to tackle and moderate more overarching variables (e.g. incentive, governance, legal, risks, reward or benefit) that affect adoptability and use of BIM for social collaboration (Succar, 2009 ; Porwal \& Hewage, 2013 ; Lam et al., 2017 ; Abdulaal et al., 2017 ; Ariffin et al., 2018). There is a need to move away from the fragmented practice that characterizes the project to an approach focused on more collaborative practice. Alternative contracting models such as integrated project delivery (IPD), project alliance, project partnerships and integrated procurement method (Succar, 2009; Kent \& Becerik, 2010; Rekola et al, 2010; 
Sebastian, 2010; Cao et al., 2015; Papadonikolaki et al., 2016; Mignone et al., 2016; Abdulaal et al., 2017; Liao et al., 2017; Hall et al., 2018; Merschbrock et al., 2018; Jang et al., 2018; Ariffin et al., 2018, Wong, 2018) are proven to be successful platform for nurturing collaborative relationships through collaborative elements (e.g. incentive arrangements joint governance structure, co-location etc) (Dossick \& Neff, 2010 ; Walker \& LloydWalker, 2015; Papadonikolaki et al., 2016; Che Ibrahim et al., 2017 ; Jang, 2018, Teng et al., 2018). Adopting $\mathrm{BIM}$ in the AEC industry, not only requires the knowledge related to technology, but also need to have knowledge of intellectual property protection especially for common data (e.g. models, drawings and information). Therefore, clear ownership right, responsibilities of the BIM data and data security protected should be included in contract documents. Thus, based on this approach, it would prompt project members to protect their own confidential data, eager to share information and collaborate together (Zhao et al., 2018).

In addition, to ensure the stabilization of BIM collaboration, government with supporting agency needs to execute the continuos assessment arrangement in achieving persistent BIM collaboration - project based (e.g. audit assessment, controlling and monitoring, consultancy and research arrangement) (Succar, 2009; Mamter \& Aziz, 2016; Kouch et al., 2018). According to IECEE (2019), proficiency testing program (PTPs) has been conducted in the national and international level to determine the real capability of certification body testing laboratories focused on the inter-laboratory. Thus, in the BIM spectrum this concept of proficiency programme need to be emphasized in achieving the successful of BIM collaboration especially among organisation and also project members through practically use the BIM tool. In the Malaysia context, this proficiency program could be executing among responsible bodies (i.e Construction Industry Development Board (CIDB)) with cooperation government agency where in this proficiency programme, all of organisations and project members will be evaluated for their real capability using BIM tool where directly contribute to the successful of BIM collaboration.

In addition, in navigate the BIM collaboration, the competency assessment need to be executed by responsible bodies across the project members and organisation to enhance the solid BIM collaboration. In the facility management context by Gial and Issa (2016), they have found that the competencies assessment is an expedite approach to achieve BIM collaboration and implementation where the owners can assess their technical knowledge, improve their current BIM requirement and increase the efficiency of their construction operations through competencies domains (i.e. strategic, administrative and operation). In the BIM collaboration context, this competencies assessment value can play a vital role in improving the maturity of future BIM among project members and organisation where collaborate together. Through competencies assessment, it can provide the baseline or benchmark for organization stands and possible areas for continuous improvement where directly achieve the successfulness of BIM collaboration. Thus, the successful social collaboration in BIM-enabled project can only be achieved through purposeful integration of these five main elements that fully support the end users' goals.

\section{CONCLUSION}

This paper presents a review of key elements of social collaboration achievement in BIM-enabled project. In essence, the social collaboration achievement is a result of a combination of five key elements; Organisational Perspective, Foundational Setting, Behavioural Perspective, Enforcement Platform and Educational Perspective. The need of these five elements is crucial to ensure the continuous interaction and positive relationships between the project team members.

It is worth highlighting that a widespread adoption of BIM in construction industry requires a highly social collaborative practice that can demonstrate the holistic approach in order to deliver full potential of BIM to the end user. Overall, the nexus of social collaboration (shown in Figure 1) are considered as the theoretical lens of the future study. Consequently, the next phase of this research aims to expand this framework further, through validating and benchmarking to capture the gaps lie within these elements and their relationships within the digital context.

\section{REFERENCES}

Abdulaal, B., Bouferguene, A., \& Al-Hussein, M. (2016). Benchmark Alberta's Architectural, Engineering and Construction Industry Knowledge of Building Information Modelling (BIM). Canadian Journal of Civil Engineering, 44(1), 59-67. doi:https://doi.org/10.1139/cjce-2014-0296. 
Alreshidi, E., Mourshed, M., \& Rezgui, Y. (2016). Cloud-Based BIM Governance Platform Requirements and Specifications: Software Engineering Approach Using BPMN and UML. Journal of Computing in Civil Engineering, 30(4), 04015063. doi:http://dx.doi.org/10.1061/(ASCE)CP.1943-5487.0000539.

Akponeware, A.O., Zulfikar, A., Adamu, Z.A., (2017). Clash Detection or Clash Avoidance? An Investigation into Coordination Problems in 3D BIM, Buildings, 7(3), 1-28.

Al-Hattab, M \& Hamzeh, F (2018). Simulating The Dynamics Of Social Agents And Information Flows In BIMBased Design, Automation in Construction, 92, 1-22.

Ariffin, H. L. T., Raslim, F. M., Cun, K. C., \& Mustaffa, N. E. (2018). Factors Concerning Procurement Selection in Building Information Modelling (BIM) Projects Paper presented at the 2017 International Conference on Research and Innovation in Information Systems (ICRIIS).

Bassanino, M., Fernando, T., Wu, K.-C., 2014. Can Virtual Workspaces Enhance Team Communication And Collaboration In Design Review Meetings? Arch. Eng. Design Manag. 10, 200-217.

Bozoglu, J. (2016). Collaboration and Coordination Learning Modules For Bim Education. Journal of Information Technology in Construction, 21, 152-163. doi:http://www.itcon.org/2016/10.

Burcin, B.-G., Gerber, D. J., \& Ku, K. (2011). The Pace Of Technological Innovation In Architecture, Engineering, And Construction Education: Integrating Recent Trends Into The Curricula. Journal of Information Technology in Construction, 16, 411-432. doi:, http://www.itcon.org/2011/24.

Cao, D., GuangbinWang, Li, H., Skitmore, M., Huang, T., \& Zhang, W. (2015). Practices And Effectiveness Of Building Information Modelling In Construction Projects In China. Automation in Construction, 49, 113122.

Chau, K. W. (1997). The Ranking of Construction Management Journals. Construction Management and Economics, 15(4), 387-398. Doi:10.1080/014461997372953.

Che Ibrahim,C.K.I., Costello,S.B., Wilkinson, S., Walker, D., (2017). Innovation In Alliancing For Improved Delivery Of Road Infrastructure Projects, International Journal of Managing Projects in Business, 10(4), 700-720.

Chen, L., \& Luo, H. (2014). A BIM Based Construction Quality Management Model and its Applications. Automation in Construction, 46, 64-73. doi:http://dx.doi.org/10.1016/j.autcon.2014.05.009.

Chen, Y. (2011). A Conceptual Framework For A BIM-Based Collaboration Platform Supported by Mobile Computing. Paper presented at the Applied Mechanics and Materials.

Cidik, M.S., \& Boyd, D. (2019). Shared Sense of Purposefulness: A New Concept to Understand the Practice of Coordinating Design in Construction. Construction Management and Economics, DOI: $10.1080 / 01446193.2019 .1593471$

Deniz, G. O. (2018). Emerging Cad And BIM Trends In The Aec Education: An Analysis From Students' Perspective. Journal of Information Technology in Construction, 23, 138-156. doi:http://www.itcon.org/2018/7.

Ding, Z., Zuo, J., Wu, J., \& Wang, J. Y. (2015). Key Factors For The BIM Adoption By Architects: A China Study. Engineering, Construction and Architectural Management, 22(6), 732-748.

Dossick, C. S., \& Neff, G. (2010). Organizational Divisions in BIM-Enabled Commercial Construction. Journal of Construction Engineering and Management, 136(4), 459-467. doi:10.1061/ ASCE CO.19437862.0000109.

Eleftheriadisa, S., Duffour, P., \& Mumovica, D. (2018). Participatory Decision-Support Model In The Context Of Building Structural Design Embedding BIM With QFD. Advanced Engineering Informatics, , 38, 695711. doi:https://doi.org/10.1016/j.aei.2018.10.001. 
Enshassi, A., AbuHamra, L., \& Mohamed, S. (2016). Barriers to implementation of Building Information Modelling (BIM) In the Palestinian Construction industry. International Journal of Construction Project Management, 8(2).

Giel, B., \& Issa, R. R. A. (2016). Framework for Evaluating the BIM Competencies of Facility Owners. Journal Management in Engineering, 32(1), 04015024.

Hall, D. M., Algiers, A., \& Levitt, R. E. (2018). Identifying the Role of Supply Chain Integration Practices in the Adoption of Systemic Innovations. Journal of Management in Engineering Construction, 34(6), 04018030 .

Harris, M., Ani, A. I. C., Haron, A. T., \& Husain, A. H. (2014). The Way Forward For Building Information Modelling (BIM) For Contractors in Malaysia. Malaysia Construction Research Journal, 15(2).

Hong, Y., M., D. W., M, C., P, A., Chan, C., F., J., \& Yeung, Y. (2012). Critical Analysis of Partnering Research Trend in Construction Journals. Journal of Management in Engineering, 28(2), 82-95. doi:http://dx.doi.org/10.1061/(ASCE)ME.19435479.0000084.

Hosseini, M.R., Banihashemi, S., Chileshe, N., Namzadi, M.O., Udaeja, C., Rameezdeen, R., McCuen, T., 2016. BIM Adoption Within Australian Small And Medium-Sized Enterprises (Smes): An Innovation Diffusion Model. Construct. Econ. Build. 16, 71-86.

Ibrahim, N.H., (2013) Reviewing The Evidence: Use Of Digital Collaboration Technologies In Major Building And Infrastructure Projects, Journal of Information Technology in Construction (ITcon), 18, 40-63.

IECEE. (2019). IEC System of Conformity Assessment Schemes for Electrotechnical Equipment and Components. Retrieved February 1, https://www.iecee.org/committees/ctl/proficiencytest/.

Ilich M, Becerik B, Aultman B (2006) Online Collaboration: Why Aren't We Using Our Tools? Publication of Architectural Engineering Institute and the Construction Institute of ASCE, vol 6, p 10.

Ishak, S. S. M., Esa, M., \& Ismail, M. H. (2017). Social Capital, Social Network and Diffusion of BIM Practices. Paper presented at the In: Chan, P W and Neilson, C J (Eds) Proceeding of the 33rd Annual ARCOM Conference, 4-6 September 2017, Cambridge, UK, Association of Researchers in Construction Management.

Jin, R., Yang, T., Piroozfar, P., Kang, B.-G., Wanatowski, D., Hancock, C. M., \& Tang, L. (2018). Project-Based Pedagogy in Interdisciplinary Building Design Adopting BIM. Engineering, Construction and Architectural Management, 25(10), 1376-1397. doi:10.1108/ECAM-07-2017-0119.

Jang, S., \& Lee, G. (2018). Impact Of Organizational Factors On Delays In Bim-Based Coordination From A Decision-Making View: A Case Study. Journal of Civil Engineering and Management, 24(1), 19-30. doi:https://doi.org/10.3846/jcem.2018.296.

Kent, D. C., \& Becerik-Gerber, B. (2010). Understanding Construction Industry Experience and Attitudes Toward Integrated Project Delivery. Journal of Construction Engineering and Management, 136, 815-825.

Kapogiannis, G., Sherratt, F. (2018). Impact Of Integrated Collaborative Technologies To Form A Collaborative Culture In Construction Projects, Built Environment Project and Asset Management, 8(1), 24-38.

Kihong, K., \& Pushkar, S. M. (2011). Building interactive modeling for construction education in virtual worlds. Journal of Information Technology in Construction (ITcon), 16, 189-208. doi:http://www.itcon.org/2011/13.

Kouch, A. M., Illikainena, K., \& Perälä, S. (2018). Key Factors of an Initial BIM Implementation Framework for Small and Medium-sized Enterprises (SMEs). Paper presented at the 35th International Symposium on Automation and Robotics in Construction (ISARC 2018).

Kokkonen, A., Vaagaasar,V.L. (2018). Managing Collaborative Space In Multi-Partner Projects. Construction 
Management and Economics, 36(2), 83-95.

Lam, T. T., Mahdjoubi, L., \& Mason, J. (2017). A Framework To Assist In The Analysis Of Risks And Rewards Of Adopting BIM For Smes In The UK. Journal of Civil Engineering and Management. doi:https://doi.org/10.3846/13923730.2017.1281840.

Li, C. Z., Fan Xueb, Xiao Lic, Jingke Hongd, \& Shene, G. Q. (2018). An Internet of Things-Enabled BIM Platform for On-Site Assembly Services in Prefabricated Construction. Automation in Construction, 89, 146-161.

Liu, Y., Van Nederveen, S., Hertogh, M. (2017). Understanding Effects of BIM on collaborative design and construction: An empirical study in China, International Journal of Project Management, 35(4), 686-698.

Liao, L., Teo, E. A. L., \& Low, S. P. (2017). A Project Management Framework For Enhanced Productivity Performance Using Building Information Modelling. Construction Economics and Building and Environment, 17(3).

Lu, W., Zhang, D., Rowlinson, S. (2013). BIM Collaboration: A Conceptual Model And Its Characteristics In: Smith, S.D and Ahiaga-Dagbui, D.D (Eds) Procs 29th Annual ARCOM Conference, 2-4 September 2013, Reading, UK, Association of Researchers in Construction Management, 25-34.

Lu, Y., Li, Y., Skibniewski, M., Wu, Z., Wang, R., Le, Y. (2015). Information and Communication Technology Applications in Architecture, Engineering and Construction Organization: A 15-Year Review, Journal Management Engineering, 31, 1-11.

Ma, Z., Zhang, D., \& Li, J. (2018). A Dedicated Collaboration Platform for Integrated Project Delivery. Automation in Construction, 86, 199-209.

Mamter, S., \& Aziz, A. R. A. (2016). Holistic BIM Adoption and Diffusion in Malaysia Paper presented at the MATEC Web of

Memon, A. H., Rahman, I. A., Memon, I., \& Azman, N. I. A. (2014). BIM in Malaysian Construction Industry: Status, Advantages, Barriers and Strategies to Enhance the Implementation Level Research Journal of Applied Sciences, Engineering and T

Merschbrock, C., Munkvold, B. E. (2015). Effective Digital Collaboration In The Construction Industry - A Case Study Of BIM Deployment In A Hospital Construction Project, Computers in Industry, 73, 1-7.

Merschbrock, C., Hosseini, M. R., Martek, I., Mehrdad, Arashpour, \& Mignone, G. (2018). Collaborative Role of Sociotechnical Components in BIM-Based Construction Networks in Two Hospitals. Journal Management in Engineering, 34(4), 05018006. doi:https://doi.org/10.1061/(ASCE)ME.19435479.0000605.

Mignone, G., Hosseini, M. R., Chileshe, N., \& Arashpour, M. (2016). Enhancing Collaboration In Bim-Based Construction Networks Through Organisational Discontinuity Theory: A Case Study Of The New Royal Adelaide Hospital. Architectural Engineering and Design Management. doi:http://dx.doi.org/10.1080/17452007.2016.1169987.

Musa, S, Ponting, A.M, Nifa, F.A.A \& Shahron, S. A (2018). Building Information Modelling (BIM) in Malaysian Construction Industry: Benefits and Future Challenges.

Mulrow, C. D (1994). Rationale For Systematic Reviews, BMJ:British Medical Journal, 309(6954), 597, Mohammad, W. N. S. W., Abdullah, M. R., Ismail, S., \& Takim, R. (2019). Building Information Modeling (BIM) adoption challenges for contractor's organisations in Malaysia. Paper presented at the AIP Conference Proceedings.

Nakamba, C.C., Chan, P.W., Sharmina, M. (2017). How Does Social Sustainability Feature In Studies Of Supply Chain Management? A Review And Research Agenda, Supply Chain Management: An International Journal, 22(6), 522-541. 
Oesterreich, T.D., Teuteberg, F. (2016). Understanding the Implications Of Digitisation And Automation In The Context Of Industry 4.0: A Triangulation Approach And Elements Of A Research Agenda For The Construction Industry, Computers in Industry, 83, 121-139.

Olatunji, O. A. (2011). Modelling Organizations' Structural Adjustment To Bim Adoption: A Pilot Study On Estimating Organizations. Journal of Information Technology in Construction, 16, 653-668. doi:http://www.itcon.org/2011/38.

Olawumia, T. O., Chana, D. W. M., Wong, J. K. W., \& Chana, A. P. C. (2018). Barriers To The Integration Of BIM And Sustainability Practices In Construction Projects: A Delphi survey of international experts. Journal of Building Engineering, 20, 60-71.

Oraee, M., Hosseini, M. R., Papadonikolaki, E., Palliyaguru, R., Arashpour, M. (2017). Collaboration in BIMBased Construction Networks: A bibliometric-qualitative literature review, International Journal of Project Management, 35, 1288 - 1301.

Owen, R., Amor, R., Palmer, M., Dickinson, J., B., C., Tatum, East, B. (2010). Challenges for Integrated Design and Delivery Solutions. Architectural Engineering and Design Management, 6, 232-240. doi:doi:10.3763/aedm.2010.IDDS1.

Papadonikolaki, E., Vrijhoef, R., Wamelink, H., \& Toh, S. H. (2016). The Interdependences Of Bim And Supply Chain Partnering: Empirical Explorations. Architectural Engineering and Design Management, 12(6). doi:http://dx.doi.org/10.1080/17452007.2016.1212693.

Patel, H., Pettitt, M., Wilson, J.R., Factors of Collaborative Working: A Framework For A Collaboration Model, Applied Ergonomics, 43, 1-26 (2012).

Petri, I., Beach, T., Rana, O. F., \& Rezgui, Y. (2017). Coordinating Multi-Site Construction Projects Using Federated Clouds. Automation in Construction, 283 83, doi:http://dx.doi.org/10.1016/j.autcon.2017.08.011.

Poirier, E.A., Forgues, D., Staub-French, S., (2017) Understanding The Impact Of BIM On Collaboration: A Canadian Case Study, Building Research and Information, 45 (6), 681-695.

Poirier, E., Forgues,D., Staub-french,S., (2016). Collaboration Through Innovation: Implications For Expertise In The AEC Sector, Construction Management and Economics, 34, 769-789.

Porwal, A., \& Hewage, K. N. (2013). Building Information Modeling (BIM) Partnering Framework For Public Construction Projects. Automation in Construction, 31, 204-214. doi:http://dx.doi.org/10.1016/j.autcon.2012.12.004.

Puolitaival, T., \& Kestle, L. (2018). Teaching And Learning In Aec Education -The Building Information Modelling Factor. Journal of Information Technology in Construction, 23, 195-214. doi:http://www.itcon.org/2018/10.

Redmond, A., Hore, A., Alshawi, M., West, M. (2012). Exploring How Information Exchanges Can Be Enhanced Through Cloud BIM, Automation in Construction, 24, 175-183.

Rekola, M., Kojima, J., \& a, T. M. (2010). Towards Integrated Design and Delivery Solutions: Pinpointed Challenges of Process Change. Architectural Engineering and Design Management, 6, 264-278. doi:10.3763/aedm.2010.IDDS4.

Sacks, R., Radosavljevic, M., \& Barak, R. (2010). Requirements For Building Information Modeling Based Lean Production Management Systems For Construction. Automation in Construction, 19, 641-655.

Sebastian, R., \& Berlo, L. o. v. (2010). Tool for Benchmarking BIM Performance of Design, Engineering and Construction Firms in The Netherlands. Architectural Engineering and Design Management, 6(4), 254263. 
Singh, V., Gu, N.,Wang, X., A.(2011). Theoretical Framework Of A BIM-Based Multi-Disciplinary Collaboration Platform, Automation in Construction, 20, 134-144.

Succar, B. (2009). Building Information Modelling Maturity Matrix: Handbook of Research on Building Information Modeling and Construction Informatics: Concepts and Technologies.

Succar, B., Sher, W., \& Williams, A. (2013). An Integrated Approach To Bim Competency Assessment, Acquisition And Application. Automation in Construction, 35, 174-189. doi:http://dx.doi.org/10.1016/j.autcon.2013.05.016.

Teng, N. C., Tob, S. U. M., \& Fathi, M. S. (2018). Current Bim Practices In Malaysian Construction Organisations: The Stakeholders' Perspective. Malaysia Construction Research Journal, 3(1).

Tserng, H.-P., Hoa, S.-P., \& Jana, S.-H. (2014). Developing Bim-Assisted As-Built Schedule Management System For General Contractors. Journal of Civil Engineering and Management, 20(1), 47-58. doi:http://dx.doi.org/10.3846/13923730.2013.851112.

Van Gassel, F., Láscaris-Comneno, T. \& Maas, G. 2014, 'The Conditions for Successful Automated Collaboration in Construction', Automation in Construction, vol. 39, pp. 85-92, https://doi.org/10.1016/j.autcon.2013.12.001.

Walker, D.H.T., Lloyd-Walker, B.M. (2015). Collaborative Project Procurement Arrangements, Project Management Institute, Newtown Square, PA.

Wong, S. S. Y. (2018). A Review On The Execution Method For Building Information Modelling Projects In Hong Kong. Management, Procurement and Law, 171, 100-110. doi: https://doi.org/10.1680/jmapl.17.00055.

Ya'acob, I. A. M., Rahim, F. A. M., \& Zainon3, N. (2018). Risk in Implementing Building Information Modelling (BIM) in Malaysia Construction Industry: A Review. Paper presented at the E3S Web of Conferences (ICCEE 2018).

Yusuf, B. Y., Ali, K. N., \& Embi, M. R. (2015). Building Information Modelling (BIM): A Potential for Effective Building Industry Practice in Malaysia. Jurnal Teknologi, 77(15), 55-61.

Zaher, M., Greenwood, D., \& Marzouk, M. (2018). Mobile Augmented Reality Applications For Construction Projects. Construction Innovation, 18(2), 152-166. doi:http://dx.doi.org/10.1108/CI-02-2017-0013.

Zahrizan, Z., Nasly, M. A., Ahmad, T. H., Marshall-Ponting, A., \& Zuhairi, A. H. (2014). Exploring the Barriers and Driving Factors in Implementing Building Information Modelling (BIM) in the Malaysian Construction Industry: A Preliminary Study. Journal - The Institution of Engineers, 75(1).

Zheng, L., Lu, W., Chen, K., Chau, K.W., Niu, Y.(2017). Benefit Sharing for BIM Implementation: Tackling The Moral Hazard Dilemma in Inter-Firm Cooperation, International Journal of Project Management, 35(3), 393-405.

Zhang, S., Pan, F., Wang, C., Sun, Y., \& Wang, H. (2017). BIM-Based Collaboration Platform for the Management of EPC Projects in Hydropower Engineering. Journal of Construction Engineering and Management, 12(143).

Zhao, X., Wu, P., \& Wang, X. (2018). Risk Paths In Bim Adoption: Empirical Study Of China. Engineering, Construction and Architectural Management, 25(9), 1170-1187. doi:10.1108/ECAM-08-2017-0169. 